\title{
Snow cover and precipitation impacts on dry season streamflow in the Lower Mekong Basin
}

\author{
B. I. Cook, ${ }^{1,2}$ A. R. Bell, ${ }^{3}$ K. J. Anchukaitis, ${ }^{2}$ and B. M. Buckley ${ }^{2}$ \\ Received 6 March 2012; revised 10 July 2012; accepted 16 July 2012; published 30 August 2012.
}

[1] Climate change impacts on dry season streamflow in the Mekong River are relatively understudied, despite the fact that water availability during this time is critically important for agricultural and ecological systems. Analyses of two gauging stations (Vientiane and Kratie) in the Lower Mekong Basin (LMB) show significant positive correlations between dry season (March through May, MAM) discharge and upper basin snow cover and local precipitation. Using snow cover, precipitation, and upstream discharge as predictors, we develop skillful regression models for MAM streamflow at Vientiane and Kratie, and force these models with output from a suite of general circulation model (GCM) experiments for the twentieth and twenty-first centuries. The GCM simulations predict divergent trends in snow cover (decreasing) and precipitation (increasing) over the twenty-first century, driving overall negligible long-term trends in dry season streamflow. Our study demonstrates how future changes in dry season streamflow in the LMB will depend on changes in snow cover and precipitation, factors that will need to be considered when assessing the full basin response to other climatic and non-climatic drivers.

Citation: Cook, B. I., A. R. Bell, K. J. Anchukaitis, and B. M. Buckley (2012), Snow cover and precipitation impacts on dry season streamflow in the Lower Mekong Basin, J. Geophys. Res., 117, D16116, doi:10.1029/2012JD017708.

\section{Introduction}

[2] Water resources supplied by the Mekong River support agriculture, fisheries, ecosystems, and economic activity throughout the river basin [Adamson et al., 2009; Adamson and Bird, 2010]. Streamflow (discharge) in the Mekong River is highly seasonal and tuned to the timing of the Asian summer monsoon, with highest annual discharge occurring in late summer and early fall (September-October) and lowest discharge at the tail end of the dry season (MarchMay). The wet season flood pulse is controlled by summer monsoon precipitation and input from left-bank tributaries in Lao PDR and Vietnam, while dry season streamflow depends primarily on local precipitation and snowmelt contributions from the upper-basin in the Yunnan region of China [Adamson, 2006; Adamson et al., 2009; Kingston et al., 2011; Kiem et al., 2005]. Streamflow during the dry season is especially important for ecosystems and populations in the region, helping maintain local navigation and water quality, providing water for irrigation, and minimizing saltwater intrusion into the delta in Vietnam [Adamson et al., 2009; Adamson and Bird, 2010; Haddeland et al., 2006; Prathumratana et al., 2008]. In the

\footnotetext{
${ }^{1}$ NASA Goddard Institute for Space Studies, New York, New York, USA.

${ }^{2}$ Lamont-Doherty Earth Observatory, Palisades, New York, USA

${ }^{3}$ International Food Policy Research Institute, Washington, D. C., USA.

Corresponding author: B. I. Cook, NASA Goddard Institute for Space Studies, 2880 Broadway, New York, NY 10025, USA. (benjamin.i.cook@nasa.gov)

This paper is not subject to U.S. copyright. Published in 2012 by the American Geophysical Union.
}

face of uncertain climate change and development in the region, including deforestation [Costa-Cabral et al., 2008] and dam construction [Campbell, 2007; Grumbine et al., 2012], a solid understanding of the environmental controls on water resources in the basin is important for adequately informing risk management and policy development.

[3] Recent studies have typically focused on the response of the annual summer flood pulse in the Mekong River to climate change and other factors [e.g., Delgado et al., 2010, 2011; Västilä et al., 2010]. Climate change impacts on dry season flows are relatively understudied, despite the fact that water resources during the dry season play a critical role in regional ecosystem and societal functioning and are a priority focus for resource managers in the region [Campbell, 2007]. And while some studies have tangentially considered dry season flow in the Mekong River as part of broader analyses [e.g., Kiem et al., 2008; Kingston et al., 2011], few have explicitly quantified and discussed modern and potential future climate change impacts on flow during this season.

[4] In this study, we analyze the hydrologic controls (precipitation and snow cover) on discharge during the tail end of the dry, low flow season (March-April-May, MAM) in the Lower Mekong Basin (LMB). We focus on two gauging stations bounding the LMB along the main stem of the Mekong River: Vientiane $\left(18^{\circ} \mathrm{N}-103^{\circ} \mathrm{E}\right)$ in northern Lao PDR and Kratie $\left(13^{\circ} \mathrm{N}-106^{\circ} \mathrm{E}\right)$ in Cambodia. Our objectives are to (1) quantify the impact of Asian snow cover and regional precipitation on MAM discharge at these two sites, (2) develop robust statistical models of MAM discharge using this climate information, and (3) use these models to forecast the impact of snow cover and precipitation changes 


\section{Mekong Discharge (Pearson's r)

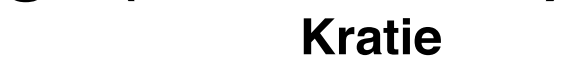

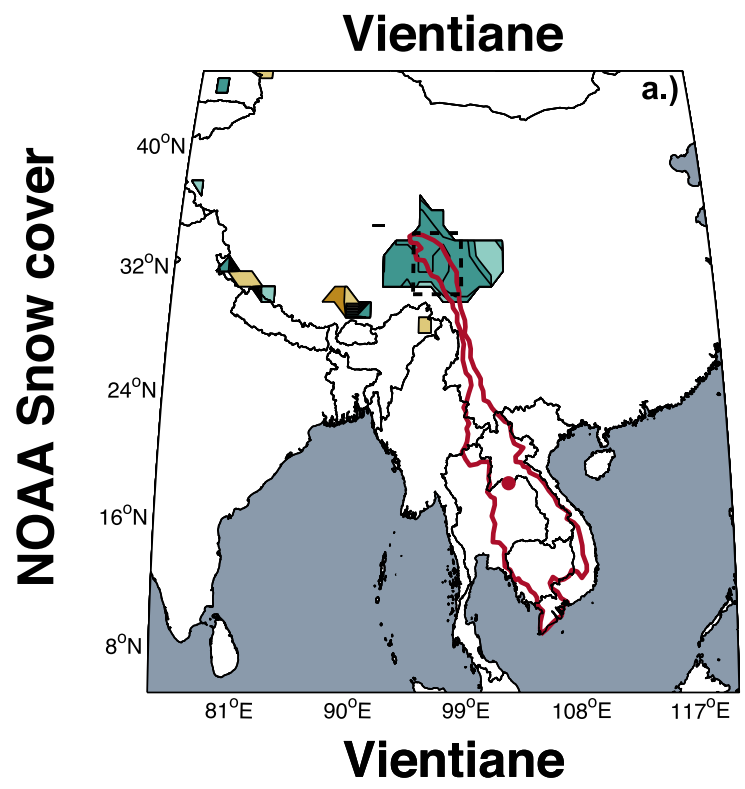
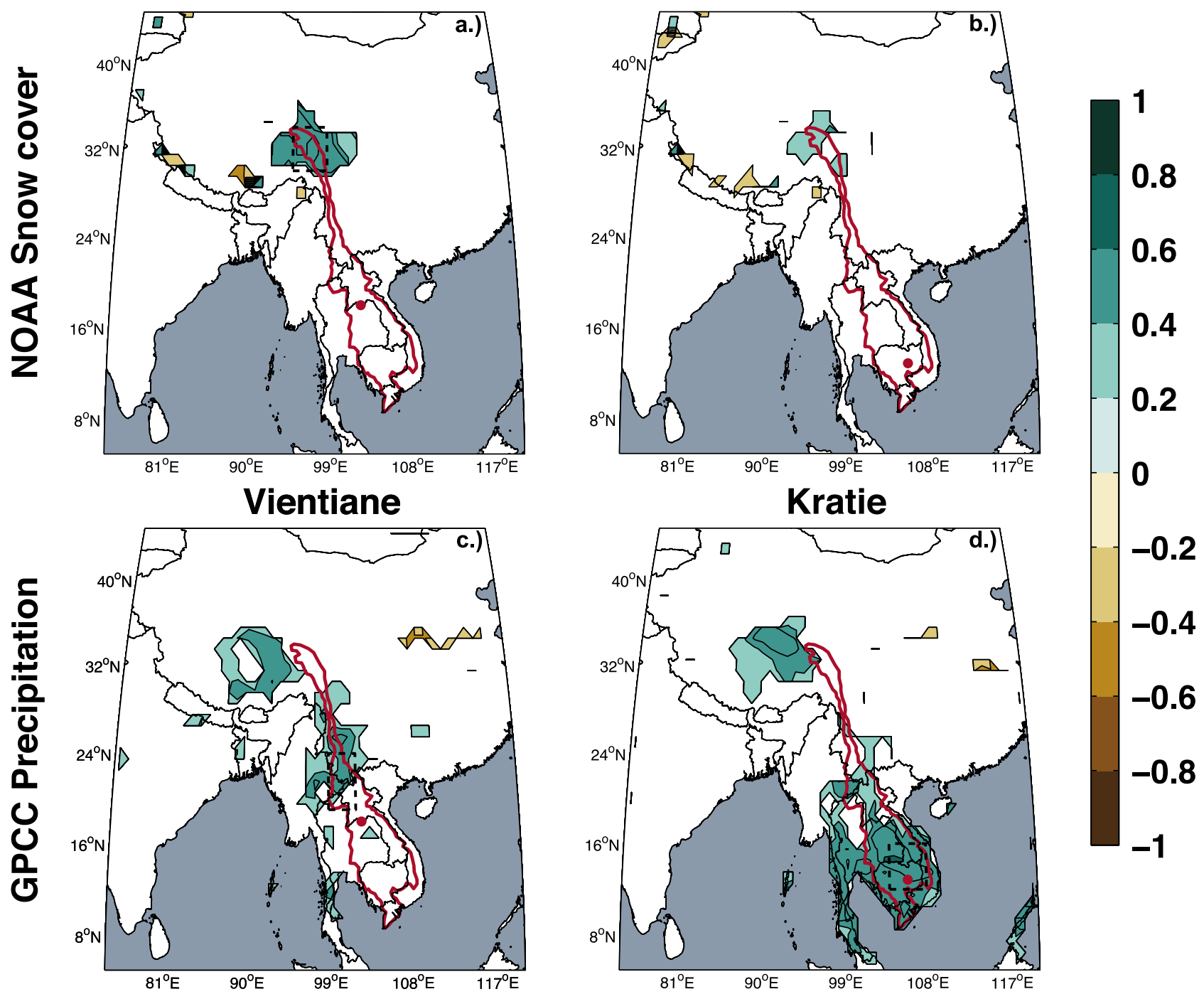

Figure 1. Pearson's correlation coefficients for the relationship between seasonal discharge (MarchApril-May) at Vientiane and Kratie and ( $a$ and b) NOAA satellite snow cover and (c and d) GPCC precipitation. The Mekong watershed is outlined in red, and the regions where the climate predictors are drawn from (see following figures) are indicated by the dashed boxes. Red dots indicate the station gauging locations. Only significant correlations $(\mathrm{p} \leq 0.05)$ are shown.

on MAM discharge using climate model projections for the twenty-first century.

\section{Materials and Methods}

\subsection{Analyses}

[5] Our methodology is based on empirical analyses of three independent data sets that are then used to develop relatively parsimonious statistical models. This approach is not intended to replace or supersede studies that have addressed related research questions using process based distributed hydrologic models (DHMs) [e.g., Kingston et al., 2011; Kite, 2001]. Rather, our study serves in a complementary capacity, offering different advantages compared to
DHM studies. For example, DHMs and other process oriented models often require diverse data inputs that are often not readily available over broad temporal and spatial scales, or may be of unknown or undocumented quality, especially in developing regions. This is especially true for non-standard atmospheric variables for which data coverage is especially sparse, such as radiation, humidity, and cloud cover. Our models and analyses require only three independent, longterm, and quality controlled data sets: snow cover, precipitation, and streamflow. Many process-based models, including DHMs, also require estimates of many poorly known parameters related to the land surface, vegetation, and surface fluxes (e.g., surface roughness, aerodynamic/vegetation resistance, infiltration capacity, etc.). Explicitly accounting for these 
Snow Fraction (Vientiane), fraction
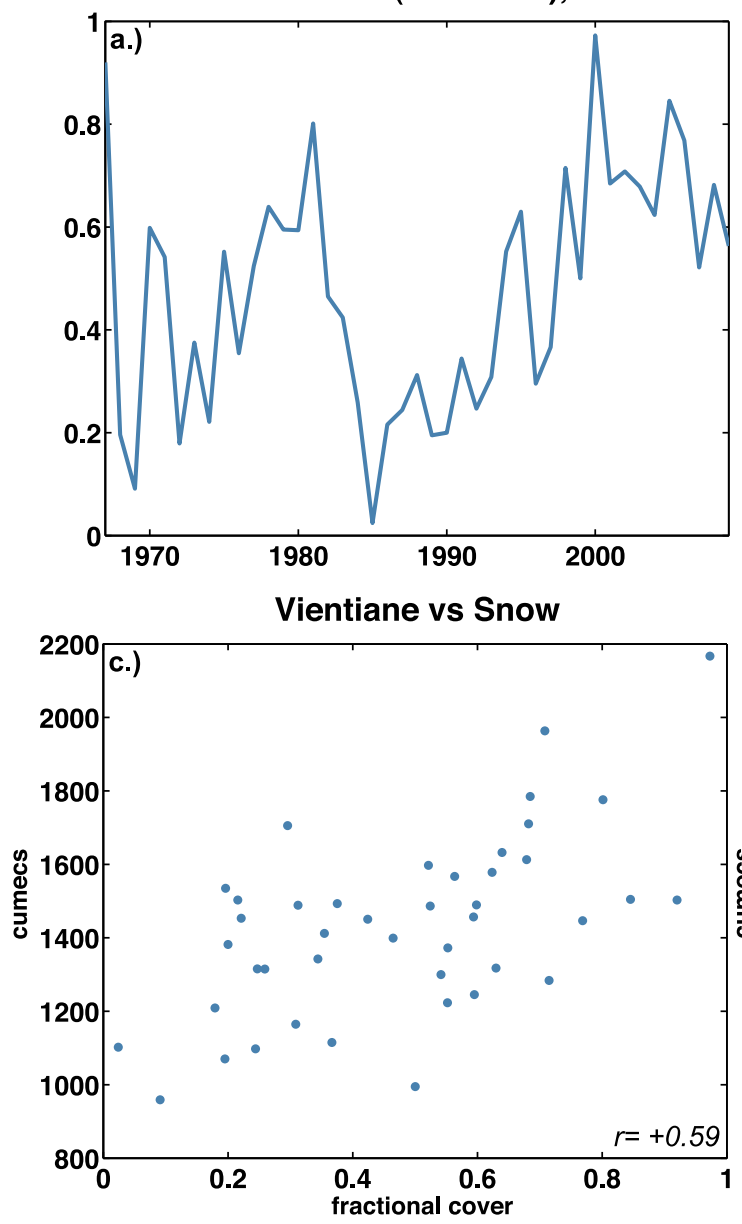
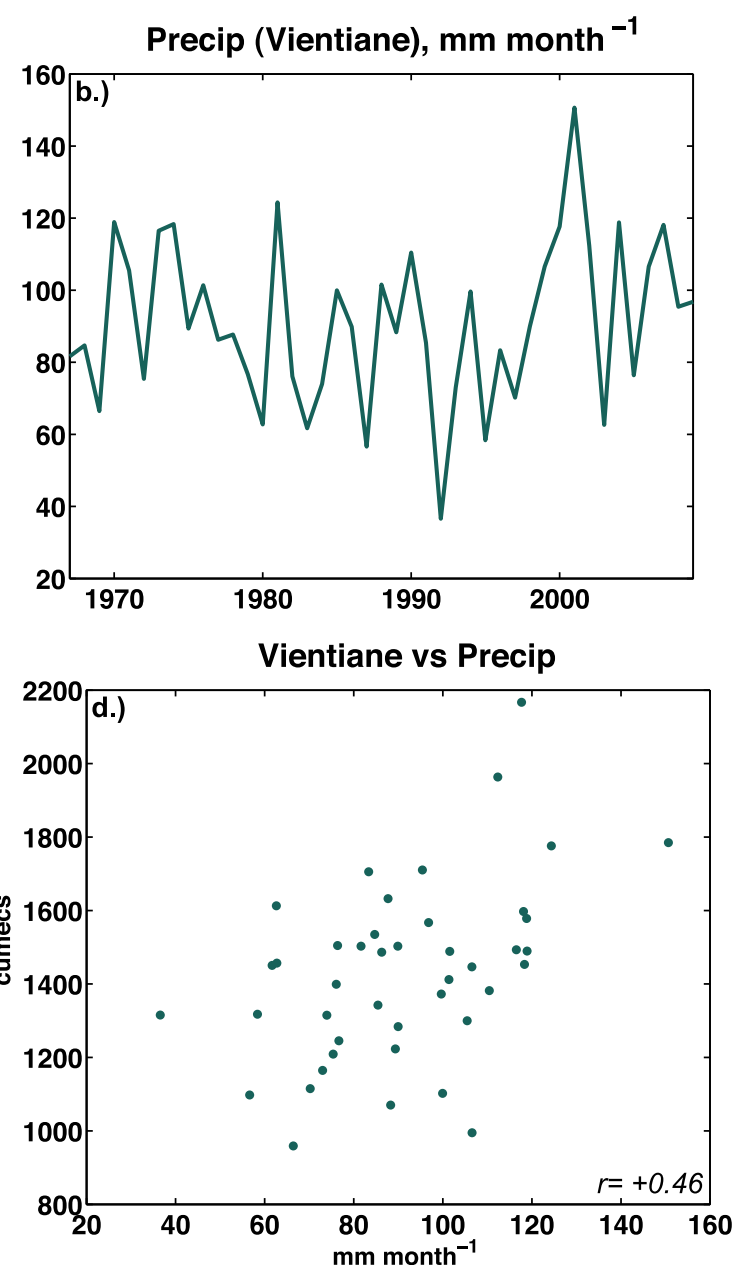

Figure 2. Time series of (a) snow cover and (b) precipitation predictors used to develop the Vientiane regression model. (c and d) Correlations between these two predictors and Vientiane discharge are positive and highly significant $(\mathrm{p} \leq 0.01)$.

factors is not necessary in our model: any impact these would have on the relationship between streamflow and snow cover or precipitation is implicitly accounted for in the analyses and model fitting. Finally, from a broader impacts perspective, there is strong evidence that managers, policy makers, and others who make use of climate information in an applied context strongly prefer a portfolio approach incorporating a range of methodologies [Young et al., 2006].

[6] We restrict our statistical analyses to the common time interval (1967-2009) of the three primary data sets we use: discharge measured at two sites on the Mekong River, precipitation, and satellite snow cover. Correlations are Pearson's $r$, with a significance threshold of $p \leq 0.05$. Our statistical models are multivariate linear regressions, which we calibrate and then validate using a split-sample procedure wherein half the data is withheld from the model calibration and used to test the model predictions (intervals used are 1967-1987 and 1988-2009). For validation statistics, we use validation period $R^{2}$, reduction of error $(R E)$, and coefficient of efficiency $(C E)$. The $R E$ and $C E$ statistics have theoretical ranges of minus infinity to +1 , and are based on a comparison of the model predicted values against a climatological mean value drawn from the calibration $(R E)$ or validation $(C E)$ interval.
Values of $R E$ and $C E>0$ indicate model skill that exceeds skill from the climatology. Further details on $R E$ and $C E$, and their use in climate applications, can be found in [Cook et al., 1999]. All analyses and comparisons use simultaneous (lag zero) MAM average values of the various data sets. Additional comparative analyses (not shown), in which variables were shifted to various lead or lag intervals, indicated that strongest statistical relationships were found at zero lag at the seasonal timescale.

[7] Beyond changes in the hydrologic inputs, increases in evapotranspiration driven by expected temperature increases in the future may also lead to reductions in dry season streamflow. We do not consider temperature impacts on streamflow in our analysis, however, because evapotranspiration and streamflow responses to temperature tend to be highly non-linear [Kingston et al., 2011]. This would make it difficult to fit temperature into our relatively simple analysis and modeling framework used in this study. Given this issue, and the overall importance of snow and precipitation inputs for water resources in the Mekong region, we decided to focus our analyses on the impact of changes in these hydroclimate variables, including how they vary across models and individual ensemble members. 

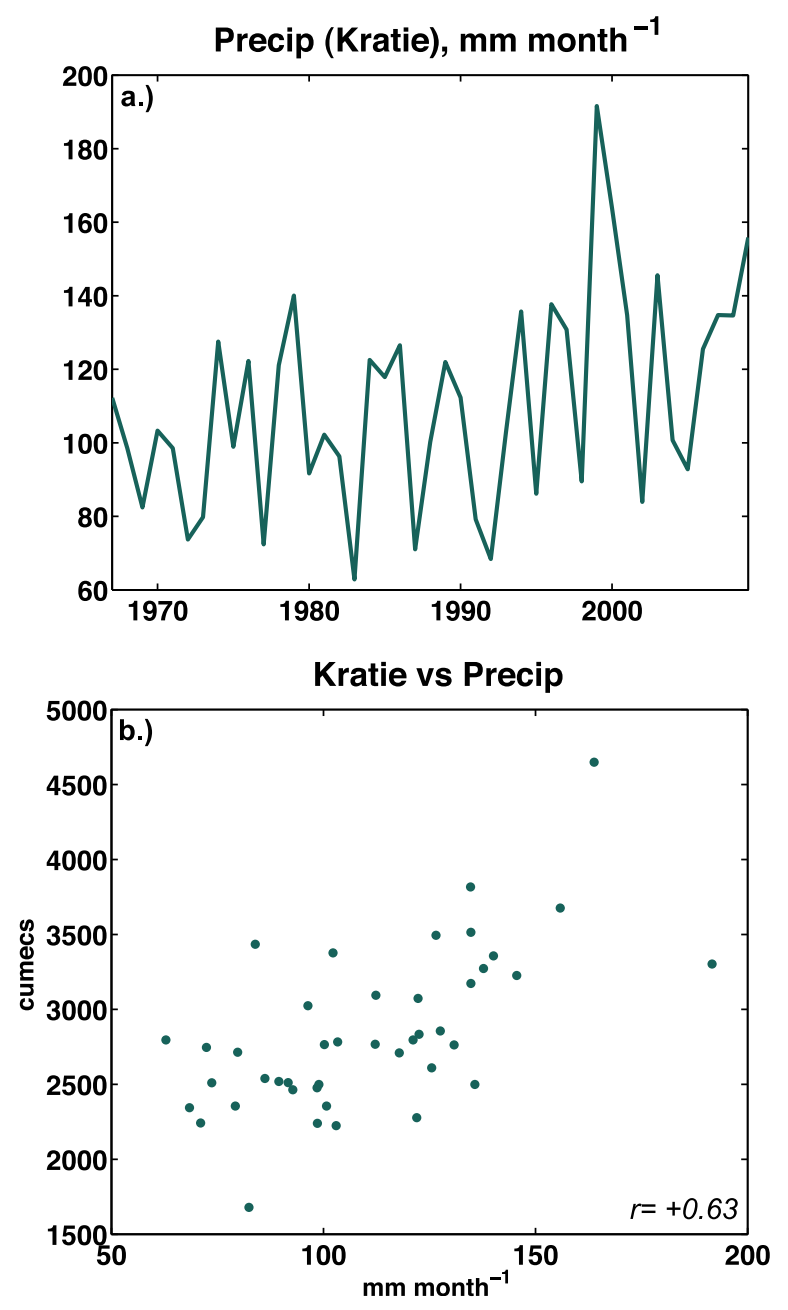

Figure 3. (a) Time series of precipitation predictor used to develop the Kratie regression model. (b) Correlation between precipitation and Kratie discharge is highly significant $(\mathrm{p} \leq 0.01)$.

\subsection{Mekong Discharge Data}

[8] Monthly discharge data (in units of cumecs, $\mathrm{m}^{3} \mathrm{~s}^{-1}$ ) for the main stem of the Mekong River are from the Mekong River Commission (MRC), the organization responsible for collating, quality controlling, and distributing data from a series of river gauging stations along the main stem of the Mekong River. Despite dam development on the Mekong River and its tributaries, as well as significant deforestation throughout the region, recent analyses have concluded that thus far these factors have had a negligible impact on Mekong River streamflow at monthly and seasonal timescales [Adamson et al., 2009; $\mathrm{Li}$ and He, 2008]. We focus our analyses on two stations that bound the northern and southern extents of the LMB [Adamson et al., 2009]. Vientiane, in Lao PDR (1913-present; catchment area 299,000 km²), represents the point along the river at which controls on discharge generally switch from snowmelt to monsoon driven. Kratie, in Cambodia (1924-present; catchment area $646,000 \mathrm{~km}^{2}$ ), represents the location on the Mekong main stem where over $90 \%$ of the integrated flow has entered the basin [Mekong River Commission, 2005]. Below Kratie, significant overbank flow makes it difficult to accurately measure mainstream discharge. These stations are considered to be physically meaningful boundaries for the LMB [Adamson and Bird, 2010].

\subsection{Climate Data}

[9] Precipitation data are from the Global Precipitation Climatology Centre (GPCC) full data reanalysis version 5 [Beck et al., 2005; Rudolf et al., 1994, 2003, 2005; Rudolf and Schneider, 2004]. The GPCC product is a reanalysis of in situ rain gauge observations, interpolated to a continuous grid across global land areas. The full data set spans 1901-2009, and is available at monthly temporal resolution. These data have been used for a variety of regional and global climate analyses [e.g., Rubel and Kottek, 2010; Wild et al., 2008; Yatagai et al., 2009]. Snow cover data is taken from the NOAA satellite snow cover product, a gridded analysis of snow cover across the Northern Hemisphere. These data are based on weekly charts of presence or absence of snow cover at each grid cell [Ramsay, 1998; Robinson et al., 1993], and are in units of percentage of days per month snow covered. The NOAA data set represents the longest temporally continuous and spatially explicit record of Northern Hemisphere snow cover available (1967-present), and has been used in a variety of climate analyses [e.g., Brown, 2000; Brown and Mote, 2009]. Here, we use this product as a proxy for the size of the snowpack and subsequent volume of water that can be supplied to the Mekong River. This assumption is supported by independent analyses demonstrating, for example, that snow depth over the Tibetan plateau is highly correlated with the number of snow covered days [You et al., 2011]. The GPCC precipitation data and the NOAA satellite snow cover product used in this study have a spatial resolution of $1^{\circ}$.

\subsection{Climate Projections}

[10] For projections of discharge into the future, we use snow cover and precipitation output from the Coupled Model Intercomparison Project version 5 (CMIP5) [Taylor et al., 2012], the latest suite of general circulation model (GCM) experiments being conducted as part of the forthcoming Fifth Assessment Report of the Intergovernmental Panel on Climate Change. We use output from the historical scenario (1950-2005, forced with observed climate forcings) and the RCP 4.5 moderate future emissions scenario (2006-2099) [van Vuuren et al., 2011]. In order to generate a snow cover metric consistent with the NOAA satellite product (representing percentage of days per month a given grid cell was snow covered), we necessarily restrict our analysis to those models that archived daily snow cover for these two scenarios. We further restricted selection to models that archived multiple ensemble members, in order to focus on the forced model responses and allow an assessment of uncertainty. We identified three models that fit these criteria: CanESM2 (Canadian Centre for Climate Modeling and Analysis; 5 ensemble members), MIROC5 (Atmosphere and Ocean Research Institute, The University of Tokyo, National Institute for Environmental Studies, and Japan Agency for Marine-Earth Science and Technology; 3 ensemble members), and MPI-ESM-LR (Max Planck Institute for Meteorology; 3 ensemble members). To account for model mean biases, precipitation and snow cover outputs were 


\section{Discharge (obs vs model)}
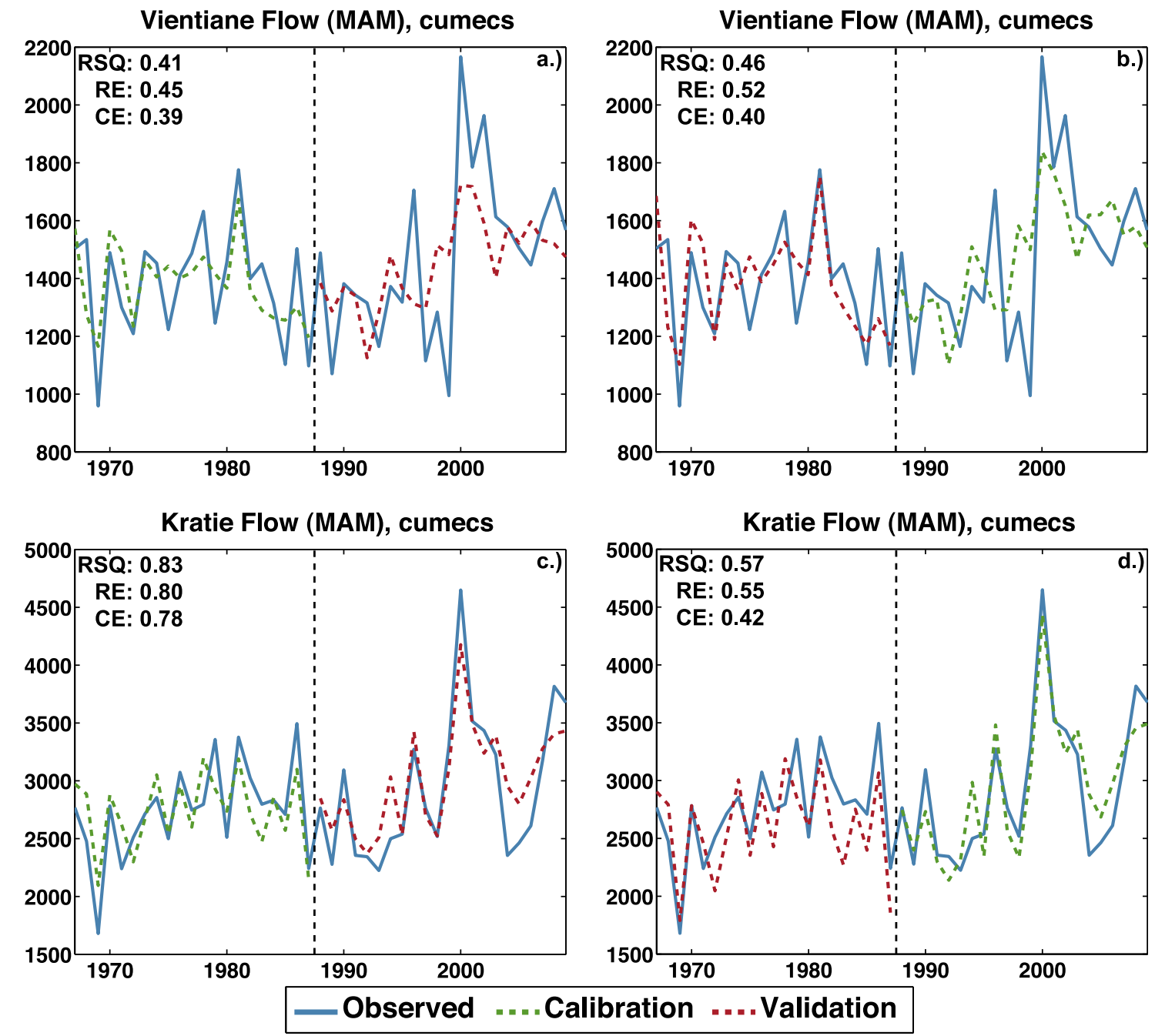

Figure 4. Results from the split sample calibration/validation procedure used to develop the regression models for ( $a$ and b) Vientiane and ( $c$ and d) Kratie. Observed discharge is in blue, the calibration period model prediction is in green, and the validation period model prediction is in red. Inset statistics represent the validation period $R^{2}$ (RSQ), $R E$, and $C E$ values.

adjusted to observed mean values using the 1967-2005 baseline, the common interval between the historical model simulations and the data. Minimum and maximum values were truncated if necessary to ensure physically realistic values $(0$ to 1 for snow cover, minimum of 0 for precipitation). Projected future changes in snow cover, precipitation, and Mekong discharge are quantified using the difference in the ensemble mean for two twenty year model periods: 1980-1999 and 2080-2099. Significance is assessed based on a two sided Student's t-test.

\section{Results}

\subsection{Correlation Analysis}

[11] Discharge at Vientiane during MAM is significantly correlated with snow cover over central Asia, including the headwaters region of the Mekong watershed (Figure 1a). Correlations between Kratie and snow cover are weaker, and less spatially extensive (Figure 1b). Streamflow at stations in the lower reaches of the Mekong Basin (such as Kratie) originates primarily from left bank tributaries and local precipitation inputs, and any apparent correlation to the upper basin is likely due to the influence of residual upstream flow. Indeed, discharge at Kratie is highly correlated with Vientiane discharge (Pearson's $r=+0.69$, $p<$ 0.001 ), supporting this explanation for the apparent correlation between Kratie and snow cover.

[12] Discharge at both Vientiane and Kratie is positively correlated with local precipitation. Regions of highest correlation for Vientiane (Figure 1c) are primarily upstream in China and Lao PDR. There is also a region of significant positive correlation over Central Asia, likely reflecting covariation between snow cover and precipitation over this region. Correlations between Kratie and precipitation (Figure 1d) are extensive over much of Indochina, demonstrating the importance of inputs from local precipitation and 


\section{CMIP5/Data Comparison (1967-2005)}
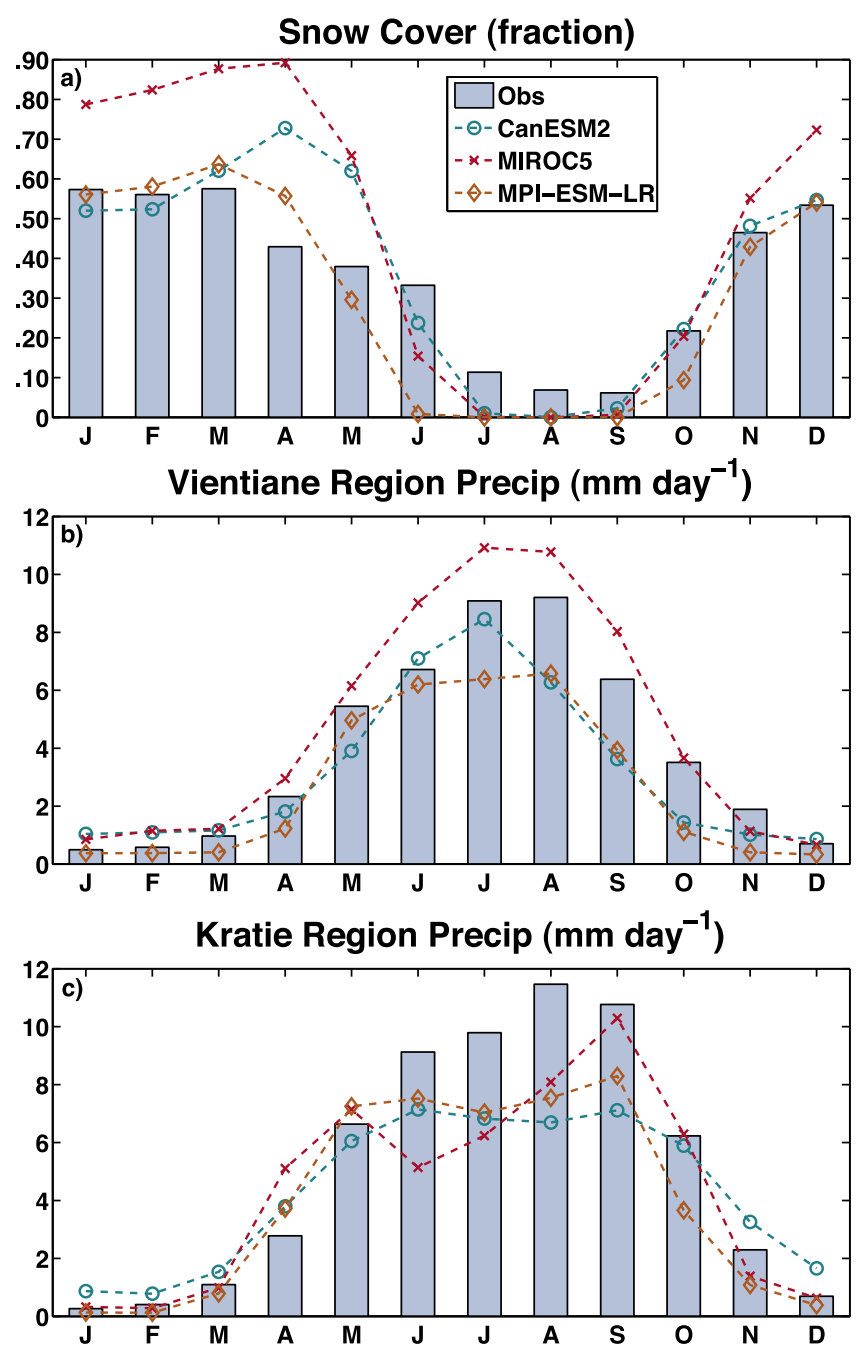

Figure 5. Comparisons between observed and modeled (a) snow cover over the Vientiane model region, (b) precipitation over the Vientiane model region, and (c) precipitation over the Kratie model region. The monthly climatology is calculated for the period 1967-2005, the common interval across the snow cover and precipitation data sets and the CMIP5 historical model simulations.

lower basin tributaries at this site. Apparent correlations between streamflow and precipitation or snow cover outside of the Mekong watershed are likely a consequence of spatial coherency in the precipitation and snow cover data. For example, the correlation decay distance used in the spatial interpolation of precipitation data is typically on the order of several hundred kilometers [Hofstra and New, 2009; Mitchell and Jones, 2005]. Correlations outside of the Mekong watershed therefore likely reflect spatial patterns of precipitation and snow cover variability, rather than direct inputs to streamflow.

[13] The correlation analysis indicates that snow cover and precipitation are potentially skillful predictors for MAM discharge at Vientiane and Kratie. We spatially average snow cover and precipitation time series over the relevant regions of high correlation for each station (Figure 1, black dashed boxes), generating new times series that can be compared against Vientiane (Figure 2) and Kratie (Figure 3) discharge. Correlation between Vientiane discharge and the snow cover time series (Figures $2 \mathrm{a}$ and $2 \mathrm{c} ; \mathrm{r}=+0.59$, $\mathrm{p}<$ 0.001 ) is slightly higher than the precipitation correlation (Figures $2 \mathrm{~b}$ and $2 \mathrm{~d} ; \mathrm{r}=+0.46, \mathrm{p}<0.01$ ). Moving south through the LMB, snowmelt contributions to streamflow are increasingly overwhelmed by inputs from local precipitation and tributaries along the left bank. At Kratie, delimiting the southern extent of the LMB, the correlation with snow cover is much weaker, although still significant $(\mathrm{r}=+0.42, \mathrm{p}<$ 0.05 ). Instead, Kratie streamflow is strongly correlated with local precipitation (Figure 3; $\mathrm{r}=+0.63, \mathrm{p}<0.001$ ), nearly the same magnitude as the correlation with upstream Vientiane discharge.

\subsection{Model Calibration and Validation}

[14] Discharge at Vientiane appears to be driven by snow cover and local precipitation inputs, and we used the snow cover and precipitation time series in Figure 2 as potential predictors for our discharge model at this location. Discharge at Kratie responds to local precipitation and also integrates flow originating from higher up in the river basin, supported by the significant positive correlation with Vientiane discharge. For our Kratie discharge model, we therefore used the precipitation time series in Figure 3 and upstream discharge at Vientiane as potential predictors. Using the Akaike information criterion (AIC) to determine predictor selection, we found that models for both sites passed a $\triangle$ AIC threshold of $\geq 2$ for inclusion of both predictors, compared to models that incorporate either single predictor alone.

[15] For our split-sample calibration and validation procedure, we split the data into two intervals (1967-1987 and 1988-2009), alternately calibrating our discharge models using data from one period and validating our model predictions on data from the independent interval. For Vientiane, our regression model explains nearly half the variability in the validation data (Figures $4 \mathrm{a}$ and $4 \mathrm{~b}$ ). Notably, the model is also able to reproduce the positive shift toward increased discharge near the start of the twenty-first century, indicating that this feature is likely climate driven rather than a data artifact or the result of non-climate influences. Indeed, both the snow cover and precipitation predictor variables (Figures $2 \mathrm{a}$ and $2 \mathrm{~b}$ ) have similar positive shifts around this time. The $R E$ and $C E$ statistics are also positive, indicating skill beyond climatology. For Kratie, the regression model is even more skillful, with validation $R^{2}$ values indicating that the model can reproduce over $80 \%$ of the variance, depending on the validation period chosen. As with Vientiane, both $R E$ and $C E$ indicate significant skill beyond climatology. As an alternative model for Kratie, we used the same local precipitation predictor but replaced Vientiane discharge with the snow cover time series that had been previously correlated against Kratie streamflow. This model was less skillful, with validation period $R^{2}$ values ranging from 0.35 to 0.49 and $\mathrm{CE}$ values from 0.22 to 0.47 , confirming the diminishing importance of snow cover impacts on streamflow in the southern reaches of the LMB. Based on these results, we retained our original Kratie model (precipitation and Vientiane discharge) for the twenty-first century model projections. 


\section{Model Snow Cover}
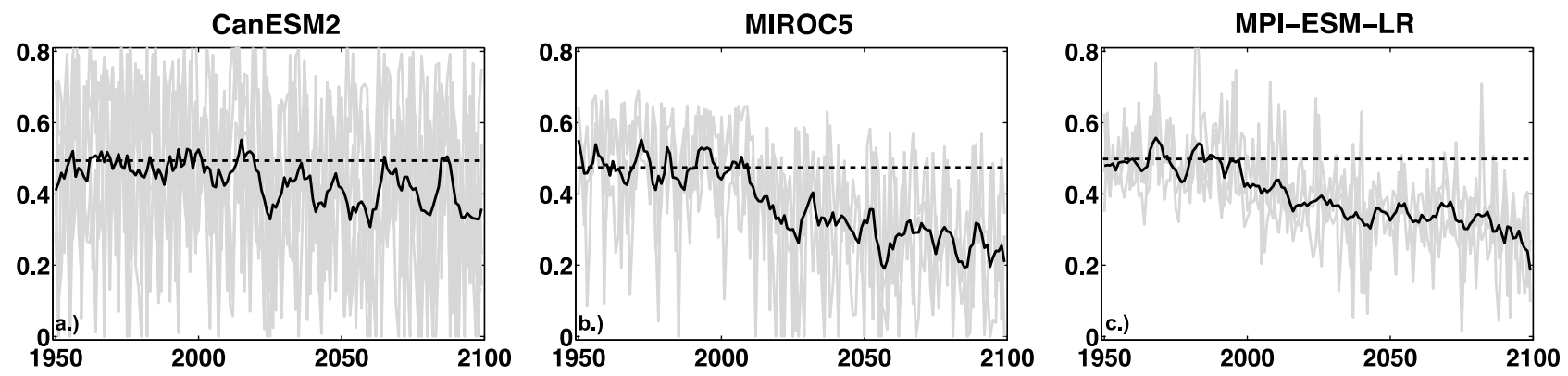

Figure 6. Snow cover (fraction) over the Vientiane snow cover region from the three GCM ensembles: (a) CanESM2, (b) MIROC5, and (c) MPI-ESM-LR. Individual ensemble members are in grey; ensemble means smoothed by averaging across a 5-year moving window are shown in solid black. Dashed line indicates the model mean for 1950-2000.

[16] Comparing the model validation statistics between our study and previous studies using DHMs is not straightforward. While our study focuses on interannual variability within one seasonal window (MAM), DHM studies typically calibrate and validate on flow in all months, including the seasonal cycle. Beyond this major difference, other studies may also use different time intervals for model validation and calibration, or even different gauging stations. Of the DHM studies we found for the Mekong Basin, Västilä et al. [2010] offers the closest comparison. Using the Variable Infiltration Capacity (VIC) model, the authors of that study compared monthly simulated and observed discharge for Kratie for 1997-2000 and found an $R^{2}$ value of 0.63. Our own Kratie model compares favorably, validating with $R^{2}$ values of 0.57 to 0.83 , depending on the interval tested. Other DHM studies [Costa-Cabral et al., 2008; Kingston et al., 2011] found, for various gauging stations in the Mekong, Nash-Sutcliffe coefficients (analogous to $R E / C E$ ) of 0.44 to 0.89 . Our $R E$ and $C E$ values generally fall within this range, albeit toward the lower end. Again, however, we note that these studies are comparing against monthly discharge, including the seasonal cycle, and using different stations and time periods for comparison. Given these caveats and differences, our models appear to provide complementary and sufficient predictive skill to allow for their use in exploring future climate impacts on MAM discharge at Vientiane and Kratie.

\subsection{Future Projections}

[17] From the CMIP5 model runs, we calculated area averaged snow cover and precipitation time series for the equivalent regions used to derive the snow cover and precipitation predictors in Figures 2 and 3. All three models reproduce the seasonality of the annual snow cover and precipitation for these regions (Figure 5), including the seasonal transitions. Two models (MIROC5 and CanESM2) overestimate snow cover during the winter and spring. Significant model precipitation biases occur primarily during the height of the summer monsoon and during the fall monsoon withdrawal, after our season of interest.

[18] In the ensemble mean, all three models show decreasing snow cover in the upper basin over the course of the twenty-first century (Figure 6). Declines are largest in the MIROC5 and MPI-ESM-LR ensembles $(-49.8 \%$ and $-40.2 \%$ respectively; $\mathrm{p} \leq 0.0001)$, while CanESM2 projects more modest, but still significant, decreases $(-19.9 \% ; \mathrm{p} \leq 0.01)$. Precipitation in the Vientiane and the Kratie regions are projected to increase in all three models (Figures 7 and 8), and the increases are largest and most significant in the MIROC5 (+37.0\%/+9.3\%, Vientiane/Kratie) and MPI-ESM-LR $(+10.3 \% /+17.0 \%$, Vientiane/Kratie) simulations. Precipitation

\section{Model Precipitation, Vientiane}
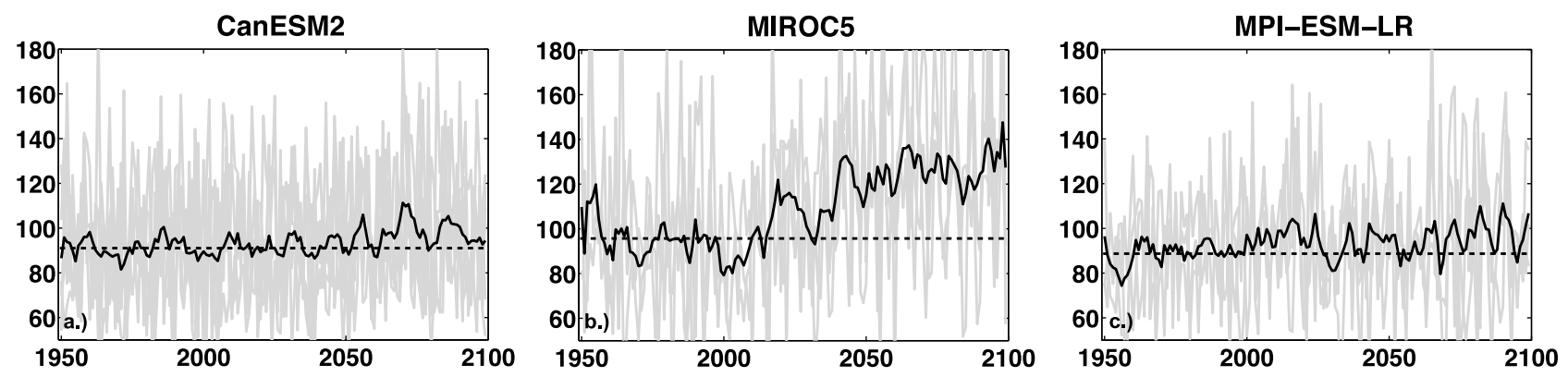

Figure 7. Precipitation ( $\mathrm{mm}$ month $^{-1}$ ) over the Vientiane precipitation region from the three GCM ensembles: (a) CanESM2, (b) MIROC5, and (c) MPI-ESM-LR. Individual ensemble members are in grey; ensemble means smoothed by averaging across a 5-year moving window are shown in solid black. Dashed line indicates the model mean for 1950-2000. 


\section{Model Precipitation, Kratie}
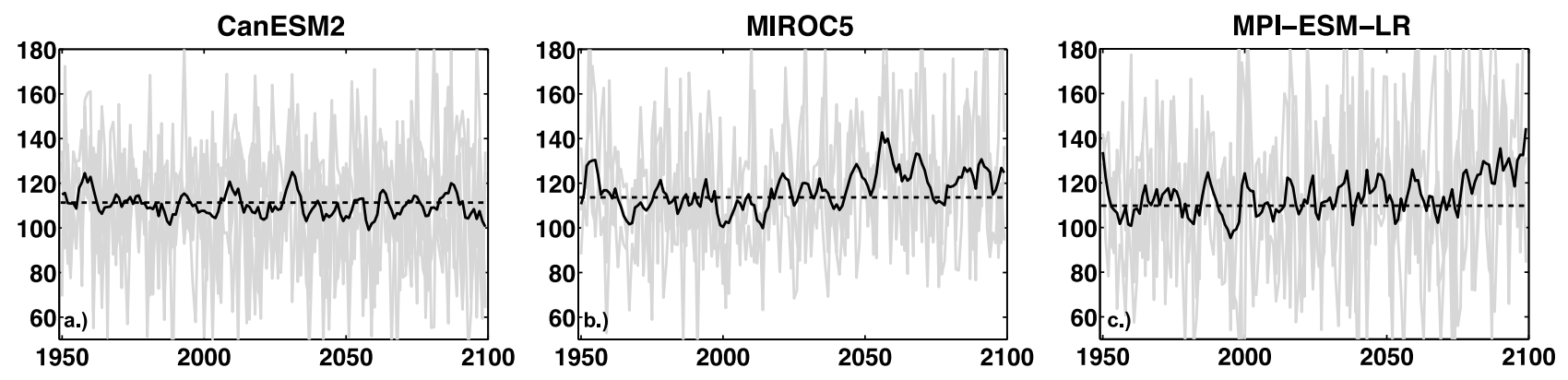

Figure 8. Precipitation ( $\mathrm{mm}$ month $^{-1}$ ) over the Kratie precipitation region from the three GCM ensembles: (a) CanESM2, (b) MIROC5, and (c) MPI-ESM-LR. Individual ensemble members are in grey; ensemble means smoothed by averaging across a 5-year moving window are shown in solid black. Dashed line indicates the model mean for 1950-2000.

increases at both locations in CanESM2 are less than $+5 \%$, and insignificant at the $\mathrm{p} \leq 0.05$ significance level. We used these climate projections to investigate climate change impacts on MAM discharge through to the end of the twenty-first century (Figures 9 and 10), conducting different experiments to isolate the impact of individual predictors. The Prec+Snow and Prec+Vient scenarios represent the full transient simulations for Vientiane and Kratie respectively, forced with transient model snow cover, precipitation, and modeled Vientiane discharge for 1950-2099. For Vientiane, the alternate experiments are Prec-Only (transient model precipitation and fixed 1950-2000 climatological model snow cover) and Snow-Only (fixed 1950-2000 climatological model precipitation and transient model snow cover). For Kratie, the alternate experiments are PrecOnly (transient model precipitation and fixed 1950-2000 climatological model Vientiane discharge) and Vient-Only (fixed 1950-2000 climatological model precipitation and transient model Vientiane discharge).

[19] For two of the models (CanESM2 and MIROC5, Figure 9a, b), ensemble mean changes in Vientiane discharge (Figure 9) are small $(-2.5 \%$ and $-0.3 \%$, respectively) and insignificant $(p>0.05)$. Changes in individual ensemble members are also insignificant, ranging from $-0.0 \%$ to $+4.4 \%$ (CanESM2) and $-1.4 \%$ to $+1.5 \%$ (MIROC5). Ensemble mean Vientiane discharge does significantly decline $(-5.1 \%)$ in the simulation using MPI-ESM-LR (Figure 9c), and all three ensemble members show significant or marginally significant decreases in discharge: $-3.9 \%(\mathrm{p} \leq 0.09),-4.8 \%$ $(p \leq 0.01)$, and $-6.7 \%(p \leq 0.05)$. In all three models, precipitation changes (blue lines) act to increase discharge at Vientiane, while the declines in snow cover (red lines) lead to decreased streamflow. Only in the MPI-ESM-LR ensemble, however, are the snow cover declines able to overwhelm the increased precipitation, leading to a significant decline in the ensemble mean discharge.

[20] As with Vientiane, results for Kratie from the CanESM2 (Figure 10a) and MIROC5 (Figure 10b) ensembles show no significant changes either in the ensemble mean or any individual ensemble member. For CanESM2, changes in individual ensemble member range from $-4.7 \%$ to $+0.7 \%$; for MIROC5 the range is $+0.4 \%$ to $+6.0 \%$. Changes in the ensemble mean for MPI-ESM-LR are similarly small (+3.1\%) and insignificant (Figure 10c), although one ensemble member does show large and significant increases in streamflow $(+11.0 \%, \mathrm{p} \leq 0.05)$. Changes in the other two ensemble members are small and insignificant, however $(-0.6 \%$ and $-1.2 \%)$. As with Vientiane, precipitation changes tend to drive increases in streamflow (green lines). In CanESM2 and MIROC5, modeled upstream Vientiane streamflow changes little and has a negligible contribution to long term Kratie streamflow (red lines). For MPI-ESM-LR, however, the significant declines in Vientiane discharge, driven by decreased snow cover and negligible precipitation trends, would act to reduce Kratie streamflow.

\section{Discussion and Conclusions}

[21] Our results highlight the impact of hydrologic inputs (snow cover and precipitation) on dry season streamflow in the Mekong River. Model validation tests indicate that these variables are robust and skillful predictors that can explain recent trends and shifts in dry season streamflow, including the increases in discharge observed near the turn of the twenty-first century. Results from the future projections using output from a suite of climate models emphasize the importance of considering the spatial heterogeneity of any climate change impacts in the Mekong River Basin, especially across models. For example, despite large and significant declines in Vientiane streamflow in the MPI-ESM-LR projections, changes at Kratie are negligible. This response contrasts sharply with the CanESM2 projections, where responses at Vientiane and Kratie, while insignificant, have similar magnitude and the same sign.

[22] As development continues throughout the Mekong Basin, streamflow during all seasons will also be increasingly influenced by non-climatic factors. Deforestation in the Mekong Basin is widespread, and likely to continue in response to a variety of economic and social drivers [Heinimann et al., 2007; Rowcroft, 2008]. Forest removal can affect surface runoff, soil moisture, and erosion throughout the basin [CostaCabral et al., 2008], with expected impacts on total water yield and the seasonal flow distribution in the Mekong River [Adamson et al., 2009]. Dam development on the main stem and Mekong tributaries is also moving at a rapid pace, with dozens of dam projects in China and Lao PDR currently in the construction or planning phase [Grumbine et al., 2012]. All of the main stem dams planned for the lower riparian states, and 
Model Discharge, Vientiane (cumecs) CanESM2
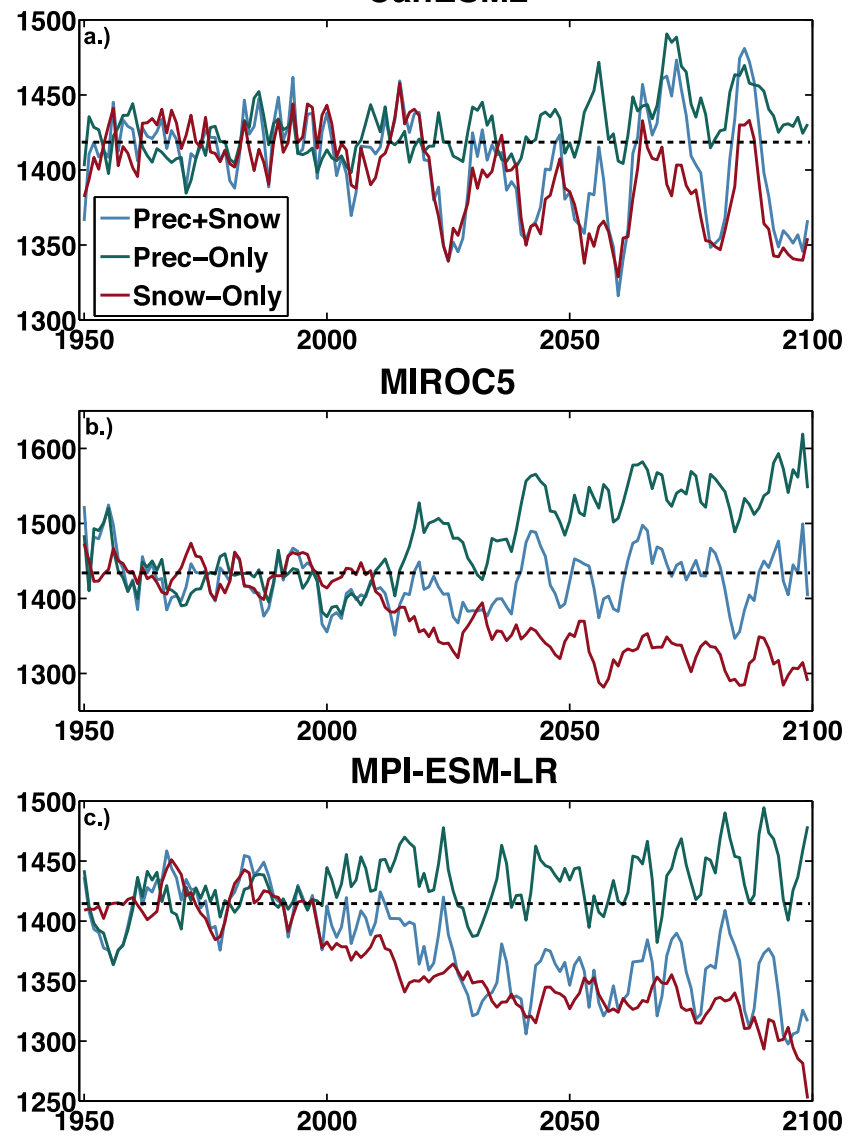

Figure 9. Ensemble average simulated discharge for Vientiane for the three GCMs: (a) CanESM2, (b) MIROC5, and (c) MPI-ESM-LR. Prec+Snow represents a scenario with full transient model projections of precipitation and snow cover. Prec-Only is forced by transient model precipitation projections and fixed twentieth-century climatological model snow cover (averaged over 1950-2000). Snow-Only is forced by fixed twentieth-century climatological model precipitation (averaged over 1950-2000) and transient model snow cover. All curves are ensemble means, smoothed by averaging across a 5-year moving window. Dashed line indicates the model mean for 1950-2000.

most of the dams in China, are 'run-of-river' dams, designed to manage electricity demand across a daily cycle with little water retention $[T u, 2011]$. And while the expectation is that these dams will shift the seasonal flow from the wet to the dry season [Adamson et al., 2009], it must be emphasized that the primary function of the dams is hydropower generation, rather than flow management, and the ultimate impact on streamflow is uncertain.

[23] Our results have two major implications for water resources in the Mekong Basin. First, reductions in snow cover may reduce discharge from China, where dam development is greatest. With these changes in the background climatology, and with flow contributions from the upper basin during the dry season expected to become increasingly controlled by non-climatic factors, improved information sharing will be critical for maintaining adequate flow for navigation and irrigation downstream. Second, should discharge in the lower basin increase as two models seem to indicate (MIROC5 and MPI-ESM-LR), this may create conflict between rice farming (which is favored by high freshwater flows) and shrimp production (which is not). The balance between these conflicting land uses is maintained by a set of defined agricultural zones and a system of sluice gates to manage fresh and brackish water flows [Hoanh et al., 2003; Dung et al., 2009]. An increase in dry season discharge in the lower basin-independently of any speculated increase due to hydropower development-is evidence that rice irrigation in the dry season may remain feasible in many areas of current production for the decades to come. Such insight can be of value both at the planning level, as the

\section{Model Discharge, Kratie (cumecs) CanESM2}
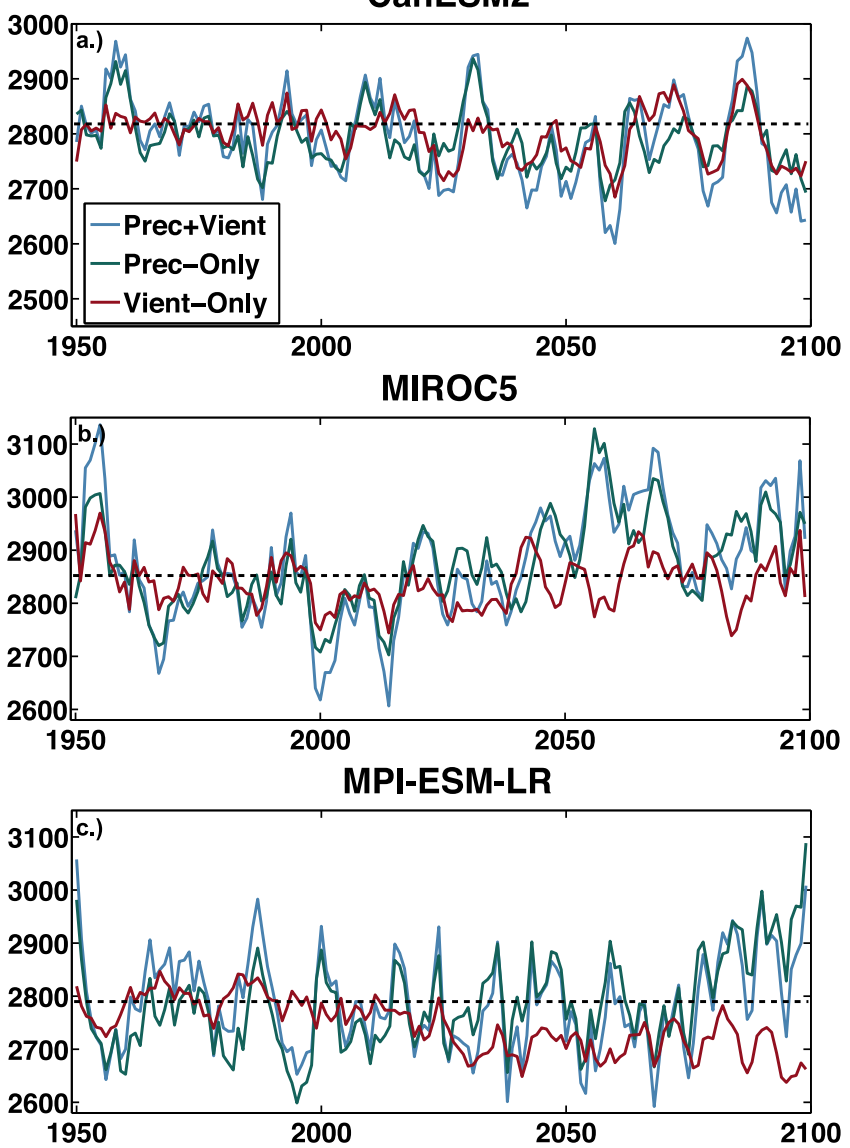

Figure 10. Ensemble average simulated discharge for Kratie for the three GCMs: (a) CanESM2, (b) MIROC5, and (c) MPI-ESM-LR. Prec+Vient represents a scenario with full transient model projections of precipitation and simulated discharge at Vientiane. Prec-Only is forced by transient model precipitation projections and fixed twentieth-century climatological modeled discharge at Vientiane (averaged over 1950-2000). Vient-Only is forced by fixed twentiethcentury climatological model precipitation (averaged over 1950-2000) and transient simulated discharge at Vientiane. All curves are ensemble means, smoothed by averaging across a 5-year moving window. Dashed line indicates the model mean for 1950-2000. 
established agricultural zoning is revisited in the future, as well as at the local commune, village, and household level as farmers living near the shrimp-rice boundaries consider how best to invest for their futures.

[24] Our statistical approach provides a clear empirical link between snow cover, precipitation, and main stem dry season discharge in the upper and lower reaches of the LMB. It provides insight into the ways in which climatic factors may drive divergent streamflow outcomes across the LMB in coming decades, which is important context in which to consider the impact from regional development, including land cover and dam construction. Natural resource decisionmaking benefits from portfolio approaches to understanding an issue [Young et al., 2006], and this study should provide a useful complement to existing simulation-based, case study, and narrative planning approaches for water resources in the Mekong River Basin.

[25] Acknowledgments. This work was supported by the Greater Mekong Basin Project (NSF Coupled Human and Natural Systems, GEO 0908971). Snow cover data were provided by Thomas Estilow and the Rutgers University Snow Lab. The authors gratefully acknowledge the Mekong River Commission (Peter Adamson and Erland Jensen) for providing the monthly Mekong River discharge data. Three anonymous reviewers provided comments that greatly improved the quality of this manuscript. We acknowledge the World Climate Research Programme's Working Group on Coupled Modeling, which is responsible for CMIP, and we thank the climate modeling groups for producing and making available their model output. For CMIP, the U.S. Department of Energy's Program for Climate Model Diagnosis and Intercomparison provides coordinating support and led development of software infrastructure in partnership with the Global Organization for Earth System Science Portals. Lamont contribution 7577.

\section{References}

Adamson, P. T. (2006), An evaluation of landuse and climate change on the recent historical regime of the Mekong, final report, Integrated Basin Flow Manage. Program, Mekong River Comm., Vientiane.

Adamson, P., and J. Bird (2010), The Mekong: A drought-prone tropical environment?, Water Resour. Dev., 26(4), 579-594.

Adamson, P. T., I. D. Rutherfurd, M. C. Peel, and I. A. Conlan (2009), The hydrology of the Mekong River, in Biophysical Environment of an International River Basin, edited by I. C. Campbell, pp. 53-76, Elsevier, New York.

Beck, C., J. Grieser, and B. Rudolf (2005), A new monthly precipitation climatology for the global land areas for the period 1951 to 2000 , in Klimastatusbericht KSB 2004, pp. 181-190, DWD, Offenbach, Germany.

Brown, R. D. (2000), Northern Hemisphere snow cover variability and change, 1915-97, J. Clim., 13(13), 2339-2355.

Brown, R. D., and P. W. Mote (2009), The response of Northern Hemisphere snow cover to a changing climate, J. Clim., 22(8), 2124-2145.

Campbell, I. C. (2007), Perceptions, data, and river management: Lessons from the Mekong River, Water Resour. Res., 43, W02407, doi:10.1029/ 2006WR005130.

Cook, E. R., D. M. Meko, D. W. Stahle, and M. K. Cleaveland (1999), Drought reconstructions for the continental United States, J. Clim., 12(4), 1145-1162.

Costa-Cabral, M. C., J. E. Richey, G. Goteti, D. P. Lettenmaier, C. Feldkötter, and A. Snidvongs (2008), Landscape structure and use, climate, and water movement in the Mekong River Basin, Hydrol. Processes, 22(12), 1731-1746.

Delgado, J. M., H. Apel, and B. Merz (2010), Flood trends and variability in the Mekong River, Hydrol. Earth Syst. Sci., 14(3), 407-418.

Delgado, J. M., B. Merz, and H. Apel (2011), A climate-flood link for the lower Mekong River, Hydrol. Earth Syst. Sci. Discuss., 8(6), 10,125-10,149, doi:10.5194/hessd-8-10125-2011.

Dung, L., C. Hoanh, C. Le Page, F. Bousquet, and N. Gajaseni (2009), Facilitating dialogue between aquaculture and agriculture: Lessons from role-playing games with farmers in the Mekong Delta, Vietnam, Water Policy, 11(S1), 80-93.

Grumbine, R. E., J. Dore, and J. Xu (2012), Mekong hydropower: Drivers of change and governance challenges, Front. Ecol. Environ., 10, 91-98, doi: $10.1890 / 110146$.
Haddeland, I., D. P. Lettenmaier, and T. Skaugen (2006), Effects of irrigation on the water and energy balances of the Colorado and Mekong river basins, J. Hydrol., 324(1-4), 210-223.

Heinimann, A., P. Messerli, D. Schmidt-Vogt, and U. Wiesmann (2007), The dynamics of secondary forest landscapes in the Lower Mekong Basin, Mt. Res. Dev., 27(3), 232-241.

Hoanh, C. T., T. P. Tuong, K. M. Gallop, J. W. Gowing, S. P. Kam, N. T. Khiem, and N. D. Phong (2003), Livelihood impacts of water policy changes: Evidence from a coastal area of the Mekong River Delta, Water Policy, 5, 475-488.

Hofstra, N., and M. New (2009), Spatial variability in correlation decay distance and influence on angular-distance weighting interpolation of daily precipitation over Europe, Int. J. Climatol., 29(12), 1872-1880, doi: $10.1002 /$ joc. 1819

Kiem, A. S., M. V. Geogievsky, H. P. Hapaurachchi, H. Ishidaira, and K. Takeuchi (2005), Relationship between ENSO and snow covered area in the Mekong and Yellow River basins, IAHS Publ., 296, 255-264.

Kiem, A. S., H. Ishidaira, H. P. Hapuarachchi, M. C. Zhou, Y. Hirabayashi, and K. Takeuchi (2008), Future hydroclimatology of the Mekong River Basin simulated using the high-resolution Japan Meteorological Agency (JMA) AGCM, Hydrol. Processes, 22(9), 1382-1394.

Kingston, D. G., J. R. Thompson, and G. Kite (2011), Uncertainty in climate change projections of discharge for the Mekong River Basin, Hydrol. Earth Syst. Sci., 15, 1459-1471.

Kite, G. (2001), Modelling the Mekong: Hydrological simulation for environmental impact studies, J. Hydrol., 253(1-4), 1-13.

Li, S., and D. He (2008), Water level response to hydropower development in the Upper Mekong River, Ambio, 37(3), 170-176.

Mekong River Commission (2005), Overview of the Hydrology of the Mekong Basin, Mekong River Comm., Vientiane.

Mitchell, T. D., and P. D. Jones (2005), An improved method of constructing a database of monthly climate observations and associated high-resolution grids, Int. J. Climatol., 25(6), 693-712.

Prathumratana, L., S. Sthiannopkao, and K. W. Kim (2008), The relationship of climatic and hydrological parameters to surface water quality in the lower Mekong River, Environ. Int., 34(6), 860-866.

Ramsay, B. H. (1998), The interactive multisensor snow and ice mapping system, Hydrol. Processes, 12(1011), 1537-1546.

Robinson, D. A., K. F. Dewey, and R. R. Heim Jr. (1993), Global snow cover monitoring: An update, Bull. Am. Meteorol. Soc., 74, 1689-1696.

Rowcroft, P. (2008), Frontiers of change: The reasons behind land-use change in the Mekong Basin, Ambio, 37(3), 213-218.

Rubel, F., and M. Kottek (2010), Observed and projected climate shifts 1901-2100 depicted by world maps of the Köppen-Geiger climate classification, Meteorol. Z., 19(2), 135-141.

Rudolf, B., and U. Schneider (2004), Calculation of gridded precipitation data for the global land-surface using in-situ gauge observations, in Proceedings of the 2nd Workshop of the International Precipitation Working Group IPWG, pp. 231-247, EUMETSAT, Monterey, Calif.

Rudolf, B., H. Hauschild, W. Rueth, and U. Schneider (1994), Terrestrial precipitation analysis: Operational method and required density of point measurements, in Global Precipitation and Climate Change, NATO ASI Ser. I, vol. 26, edited by M. Desbois and F. Désalmand, pp. 173-186, Springer, New York.

Rudolf, B., T. Fuchs, U. Schneider, and A. Meyer-Christoffer (2003), Introduction of the Global Precipitation Climatology Centre (GPCC), report, 16 pp., DWD, Offenbach, Germany.

Rudolf, B., C. Beck, J. Grieser, and U. Schneider (2005), Global precipitation analysis products, report, 8 pp., Global Precip. Climatol. Cent., Offenbach, Germany. [Available at http://www.dwd.de/bvbw/generator/ DWDWWW/Content/Oeffentlichkeit/KU/KU4/KU42/en/Reports Publications/Analysis_Products_GPCC_KSB_2004_pdf,templateId=raw, property=publicationFile.pdf/Analysis Products GPCC KSB 2004 pdf.pdf.]

Taylor, K. E., R. J. Stouffer, and G. A. Meehl (2012), An overview of CMIP5 and the experiment design, Bull. Am. Meteorol. Soc., 93(4), $485-498$.

Tu, D. T. (2011), A Vietnamese perspective on proposed mainstream Mekong dams, report, Cent. for Sustainable Dev. of Water Resour. and Adaptation to Clim. Change, Hanoi.

van Vuuren, D., et al. (2011), The representative concentration pathways: An overview, Clim. Change, 109, 5-31, doi:10.1007/s10584-011-0148-z.

Västilä, K., M. Kummu, C. Sangmanee, and S. Chinvanno (2010), Modelling climate change impacts on the flood pulse in the Lower Mekong floodplains, J. Water Clim. Change, 1(1), 67-86.

Wild, M., J. Grieser, and C. Schär (2008), Combined surface solar brightening and increasing greenhouse effect support recent intensification of the global land-based hydrological cycle, Geophys. Res. Lett., 35, L17706, doi:10.1029/2008GL034842. 
Yatagai, A., O. Arakawa, K. Kamiguchi, H. Kawamoto, M. I. Nodzu, and A. Hamada (2009), A 44-year daily gridded precipitation data set for Asia based on a dense network of rain gauges, SOLA, 5, 137-140.

You, Q., S. Kang, G. Ren, K. Fraedrich, N. Pepin, Y. Yan, and L. Ma (2011), Observed changes in snow depth and number of snow days in the eastern and central Tibetan Plateau, Clim. Res., 46(2), 171-183.
Young, O. R., et al. (2006), A portfolio approach to analyzing complex human-environment interactions: Institutions and land change, Ecol. Soc., 11(2), 31 